\title{
Plástica do púbis e da genitália externa: duas décadas de experiência
}

\author{
Plastic of the pubis and external genitalia: two decades of experience
}

Yhelda de Alencar Felicio ${ }^{1}$

Trabalho realizado na clínica privada da autora no Hospital da Santa Casa de Misericórdia de Fortaleza e no Hospital Regional da Unimed, Fortaleza, CE, Brasil.

Artigo submetido pelo SGP (Sistema de Gestão de Publicações) da RBCP.

Artigo recebido: 10/2/2011 Artigo aceito: $20 / 5 / 2011$

\begin{abstract}
RESUMO
Introdução: Este artigo registra a experiência de duas décadas de cirurgias realizadas na região do púbis e da genitália externa em pacientes de ambos os sexos. A literatura apresenta limitadas contribuições sobre as alterações morfológicas que têm levado seus portadores a se submeterem a cirurgias para retornarem à normalidade anatômica, ao equilíbrio emocional e a recuperarem a autoestima. Método: Foram operados 513 pacientes com diferentes tipos de patologias nos genitais externos e no púbis, num período de vinte anos, sendo 469 (91,42\%) do sexo feminino e 44 $(8,58 \%)$ do sexo masculino. A idade variou de 17 a 70 anos. No sexo feminino, as deformidades mais frequentes foram as distrofias do púbis, grandes e pequenos lábios, prepúcio sobre o clitóris, além das distorções secundárias decorrentes de cirurgias realizadas previamente nestas regiões. No sexo masculino, as afecções mais frequentes envolveram a região pubiana, hipotrofias penianas, sinéquias e ausência de testículos. Deformidades congênitas, além das descritas, não foram incluídas no presente artigo. Resultados: Durante o período de 1989 a 2010, os procedimentos aplicados nas disformias pubianas e nas genitálias beneficiaram pacientes física e psicologicamente, pela qualidade dos resultados e pelo baixo índice de complicações (2,31\%). Conclusões: Apesar da limitada divulgação científica nas revistas da especialidade e nos eventos científicos, a importância destas patologias não tem limite nos seus portadores. Uma das razões da presente publicação baseia-se na experiência adquirida e a necessária divulgação aos especialistas que realizam estas cirurgias, face às consequências que determinam quando não executadas dentro da necessária realidade.
\end{abstract}

Descritores: Genitália feminina/cirurgia. Genitália masculina/cirurgia. Púbis/cirurgia. Cirurgia plástica/métodos.

\begin{abstract}
Introduction: This article is the result of two decades of surgical experience in the pubic region for patients of both genders with the external genitalia dimorphic aspects. The literature presents limited contributions regarding the morphologic alterations of these regions, responsible for the patients be submitted to these surgeries to return to their normal anatomic aspects, to the emotional equilibrium and to the self-esteem. Methods: Patients of both genders, in a total of 513, with different types of pathologies of the external genitalia and the pubic regions were submitted to specific surgeries, where $469(91.42 \%)$ were female and $44(8.58 \%)$ were male. The age range was from 17 to 70 year old. In the female patients were included: dystrophies of the pubis, labia majora and minora, skin excess of the clitoris, and the treatment of other types of unacceptable results after previous surgical procedures. The male deformities included in this study were: penis hypotrophy, skin penis synechia, local angioma and the absence of congenital testicular glands. Congenital or acquired deformities out of the described were not included. Results: From 1989 to 2010 , the procedures used in the genitalia and in the pubis dimorphisms brought psychological and physic benefic to the patients combined with low complication rate (2.31\%). Conclusions: Despite of the limited scientific publications in the journals of the specialty and in the scientific meetings, the importance of these messages has no limits to their holders. One of reasons of this publication is based in acquired experience and the necessary diffusion for those that perform these surgeries but still with negative results when not performed within the necessary level.
\end{abstract}

Keywords: Genitalia, female/surgery. Genitalia, male/surgery. Pubic bone/surgery. Plastic surgery/methods.

1. Cirurgiã plástica, membro titular da Sociedade Brasileira de Cirurgia Plástica, Mestre em Cirurgia Plástica Universidade Federal do Ceará, Fortaleza, CE, Brasil. 


\section{INTRODUÇÃO}

As características anatômicas e funcionais da genitália externa, em ambos os sexos, podem interferir significativamente no comportamento das pessoas independente da idade, raça e nível sociocultural. Também não há limites dessas reações em função da extensão do problema, mesmo nas discretas alterações. Quando as características morfológicas estão fora da normalidade, problemas psicológicos podem intervir sobremaneira nas atividades sexuais, independentes dos aspectos religiosos e de educação de base. Resultados adversos pós-cirurgia do púbis e da genitália externa também comprometem, em graus variados, o psiquismo dos pacientes de ambos os sexos, com reações comportamentais diversas.

A literatura registra inúmeros trabalhos sobre o comportamento sexual, ligados às características da genitália externa ${ }^{1}$.

Procedimentos cirúrgicos dentro dos limites que buscam a correção de distorções da região pubiana e da genitália, em ambos os sexos, também estão registrados na literatura ${ }^{2-10}$. Por outro lado, procedimentos cirúrgicos de reconstruções da genitália decorrente de qualquer tipo de patologia, assim como por malformações congênitas, implantes de silicone para aumento de pênis, se encontram fora dos limites destes estudos. Os objetivos, além de discutir os aspectos táticos e técnicos empregados, são enfatizar os limites estreitos entre o resultado ideal e os efeitos indesejáveis que necessitam reparações secundárias, bem como as consequências psicológicas que podem advir, irreversíveis ou não.

\section{Aspectos anatômicos do púbis e da vulva}

A harmonia anatômica do púbis (Figura 1) e da genitália externa feminina tem características cuja avaliação e análise tem início pelos médicos e familiares no nascimento da criança, continuando ao longo da infância, da puberdade e da adulta também, por ela própria. Nas distorções que venham a ocorrer, soa um alarme psicológico para avaliação e mesmo algum tratamento, quer no sentido reparador quer funcional e mesmo estético. As características da forma e volume do púbis, dos grandes e pequenos lábios, distribuição pilosa, entre outras, sofrem alterações ao longo da vida por vários fatores, que determinam adaptações psicológicas com ou sem reivindicações de qualquer natureza. Além desses limites estabelecidos pelas próprias mulheres, este "alarme" cobra o retorno às condições prévias mediante tratamentos específicos. Dentre as solicitações estatisticamente registradas, as hipertrofias dos pequenos lábios têm sido as mais frequentes $(56,3 \%$ em nossa casuística). Sobre este detalhe, Blank ${ }^{11}$ publica um estudo em que registra, com fotografias, serem os pequenos lábios de diferentes tamanhos, concluindo pela diferença constante de dimensões entre eles. Estas conclusões foram igualmente observadas nas duas décadas de nossa experiência nesta área, sem especificar o lado predominante. Ainda dentro dos conceitos de forma e dimensões, os pequenos lábios exteriorizados até $1,5 \mathrm{~cm}$ além dos grandes lábios são considerados dentro da normalidade. Além destes limites, quanto maior o volume, o constrangimento ao se expor constitui o maior índice de queixa, seguido de desconforto para alguns tipos de vestimentas apertadas e mesmo no ato sexual . Com base nas dimensões dos pequenos lábios, há uma classificação em quatro tipos ${ }^{12}$ : Tipo I: até $2 \mathrm{~cm}$. Tipo II: de 2 a $4 \mathrm{~cm}$; Tipo III: de 4 a $6 \mathrm{~cm}$ e Tipo IV: acima de $6 \mathrm{~cm}$.

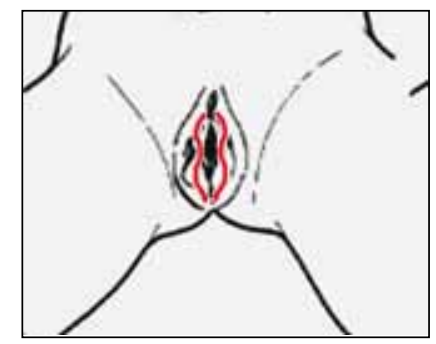

Figura 1 - Aspecto esquemático da demarcação em " $S$ " nos pequenos lábios.
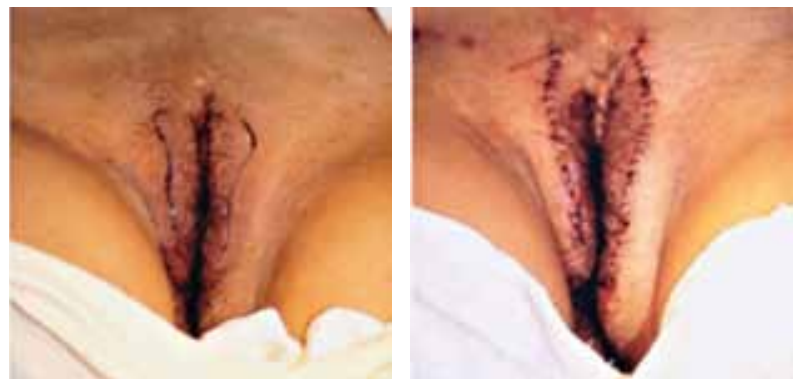

Figura 2 - Paciente de 58 anos de idade, com hipertrofia dos grandes lábios, Pré e pós-operatório imediato, incisão em " $\mathrm{S}$ " na parte central dos grandes lábios.
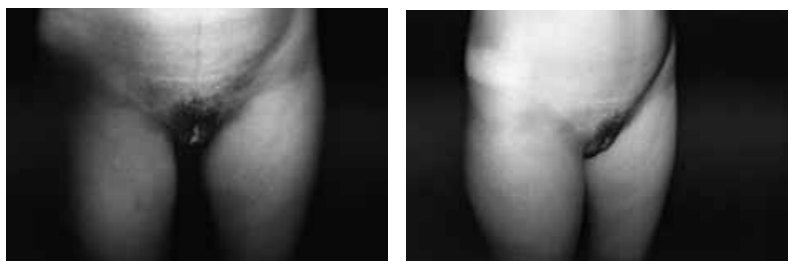

Figura 3 - Paciente de 21 anos de idade, com hipertrofia dos pequenos lábios tipo I, em que estes sobressaem (até $2 \mathrm{~cm}$ ) dos grandes lábios com seis meses de pós-operatório após ressecção dos excessos em "S".
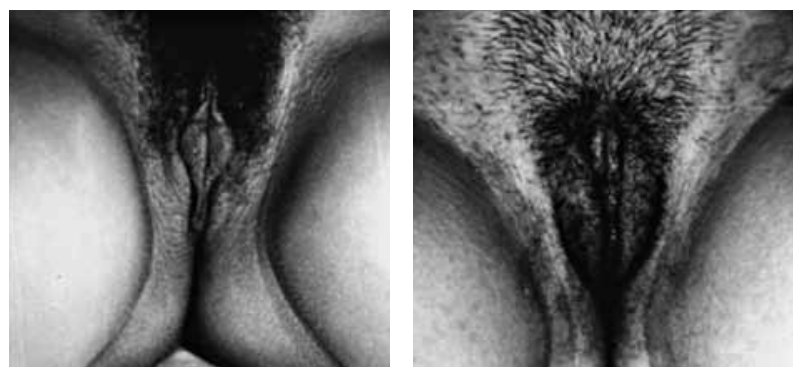

Figura 4-Paciente com 22 anos, portadora de hipertrofia dos pequenos lábios tipo II (2-4cm) seis meses de pós-operatório. 


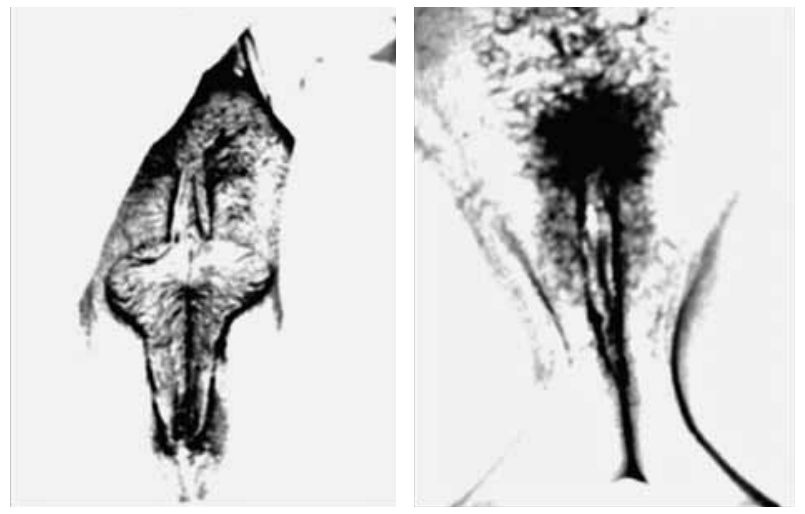

Figura 5 - Paciente de 53 anos de idade, com hipertrofia dos pequenos lábios tipo III, em que estes sobressaem de 4 a $6 \mathrm{~cm}$ dos grandes lábios, com um ano de pós-operatório, mediante ressecção em " $S$ ".
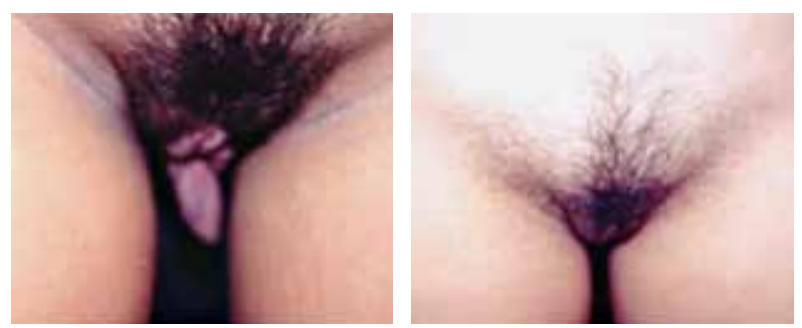

Figura 6 - Paciente de 17 anos de idade, com hipertrofia dos pequenos lábios tipo IV, em que estes sobressaem mais de $6 \mathrm{~cm}$ dos grandes lábios, com um ano de pós-operatório submetida a ressecção em " $S$ ".

\section{MÉTODO}

Foram operados 513 pacientes com diferentes tipos de patologias nos genitais externos e no púbis, num período de vinte anos, sendo $469(91,42 \%)$ do sexo feminino e $44(8,58 \%)$ do sexo masculino. A idade variou de 17 a 70 anos.

No sexo feminino, as deformidades mais frequentes foram as distrofias do púbis, grandes e pequenos lábios, prepúcio sobre o clitóris, além das distorções secundárias decorrentes de cirurgias realizadas previamente nestas regiões.

No sexo masculino, as afecções mais frequentes envolveram a região pubiana, hipotrofias penianas, sinéquias e ausência de testículos.

Deformidades congênitas, além das descritas, não foram incluídas no presente artigo.

A Tabela 1 apresenta a frequência das patologias observadas nos pacientes de ambos os sexos.

As patologias estão registradas neste grupo de doentes e listadas na Tabela 2 e as complicações na Tabela 3.
Tabela 1 - Pubisplastia e plástica da genitália externa feminina e masculina - patologias (1989-2010).

\begin{tabular}{l|c|c}
\hline Sexo & Número de casos & Percentual \\
\hline Feminino & 469 & 91,42 \\
\hline Masculino & 44 & 8,58 \\
\hline Total & 513 & 100 \\
\hline
\end{tabular}

Tabela 2 - Pubisplatia e plástica da genitália externa feminina e masculina, segundo as patologias (1989-2010).

\begin{tabular}{l|c|c}
\hline Patologias & $\mathbf{N}$ & $\mathbf{\%}$ \\
\hline Hipertrofia dos pequenos lábios & 289 & 56,30 \\
\hline Clitóris enclausurado & 118 & 23,10 \\
\hline Hipotrofia de pênis & 31 & 6,04 \\
\hline Hipotrofia dos grandes lábios & 31 & 6,04 \\
\hline Hipotrofia do púbis feminino & 17 & 3,31 \\
\hline Hipertrofia do púbis feminino & 10 & 1,94 \\
\hline Hipertrofia do púbis masculino & 8 & 1,55 \\
\hline Ausência de pequenos lábios & 3 & 0,58 \\
\hline Ausência de testículos & 2 & 0,38 \\
\hline Sinéquia de freio de pênis & 2 & 0,38 \\
\hline Pequeno lábio supranumerário & 1 & 0,19 \\
\hline Hemangioma de pênis & 1 & 0,19 \\
\hline Total & 513 & 100 \\
\hline
\end{tabular}

Adiposidade pubiana combinada com as dos grandes lábios pode ser removida mediante lipoescultura com seringa das regiões e ressecção transversal arciforme dos excessos de pele no contorno superior do púbis, quando necessário (Figuras 8A e 8B).

Hipotrofia do púbis, com ou sem hipotrofia dos grandes lábios, é tratada com lipoenxertia seletiva, com seringa isenta de sangue, após lavagem com solução salina. O processo compreende lavagem continuada até a eliminação total do sangue, mantendo a seringa fechada de $20 \mathrm{cc}$ até o momento de ser implantada. O volume varia em função das condições locais; no púbis, tem sido entre 100 a $200 \mathrm{ml}$ e 10 a $30 \mathrm{ml}$ nos grandes lábios, numa única sessão (Figuras 9A-9D e 10).

Os cuidados pós-operatórios em todos os tipos de cirurgia compreendem abstenção sexual e banhos de imersão por 40 dias. Uso de bolsas geladas por 15 minutos, 5 vezes ao dia, durante os sete primeiros dias de pós-operatório. Drenagem linfática é indicada por 40 minutos, três vezes por semana, durante 15 primeiros dias de pós-operatórios. 


\section{Técnica Cirúrgica}

Todas as cirurgias foram realizadas em hospitais ou na clínica, com internamento, sob sedação com benzodiazepínicos via oral ou endovenosa e anestesia local com xilocaína a $1 \%$ sem epinefrina.

Todos os pacientes receberam antibióticos a base de cefalosporina $1 \mathrm{~g}$ duas horas antes da cirurgia, via intramuscular ou endovenosa, e $4 \mathrm{~g}$ diários, por sete dias via oral, bem como foi prescrito anti-inflamatório (diclofenato de sódio) $70 \mathrm{mg}$, a cada oito horas, durante uma semana no pós-operatório. Atividades esportivas, sexuais, piscina e mar foram liberadas após 40 dias. Tipos de curativos e cuidados locais variaram de acordo com os tipos de cirurgia.

\section{Pubisplastia e plástica da genitália externa feminina}

$\mathrm{Na}$ hipertrofia isolada combinada com flacidez dos pequenos lábios, a cirurgia compreende a ressecção cutânea em cunha, ao longo do seu eixo maior, na forma de "suave S" ao longo da curvatura, e sutura contínua com fio absorvível Vicryl 4-0 (Figura 1). Igualmente nas hipertrofias de grandes lábios (Figura 2A e 2B). Os graus de hipertrofia dos pequenos lábios são distribuídos em quatro tipos em função do volume e da extensão que sobressaem os grandes lábios. As ressecções são similares em forma de "S" e específicas com os excessos, respeitando um limite de até $1,5 \mathrm{~cm}$ fora no nível dos grandes lábios. Tipo I: (Figuras 3A e 3B), Tipo II: (Figuras 4A e 4B) Tipo III: (Figuras 5A e 5B), Tipo IV: (Figuras 6A e 6B). O tratamento do púbis mediante lipoenxertia ou lipoaspiração pode ser realizado concomitantemente.

Nos casos de excedentes de pele que encobrem parcial ou totalmente o clitóris, formando um tipo de prepúcio, além dos excessos de pequenos lábios, a cirurgia compreende a ressecção bilateralmente, mediante dois fusos de pele que cobrem o clitóris. A síntese cutânea é realizada mediante sutura contínua de material absorvível Vicryl 4-0 (Figuras 7A e 7B). Ressecções em "S" dos pequenos lábios são indicadas seletivamente no mesmo ato operatório se necessárias.
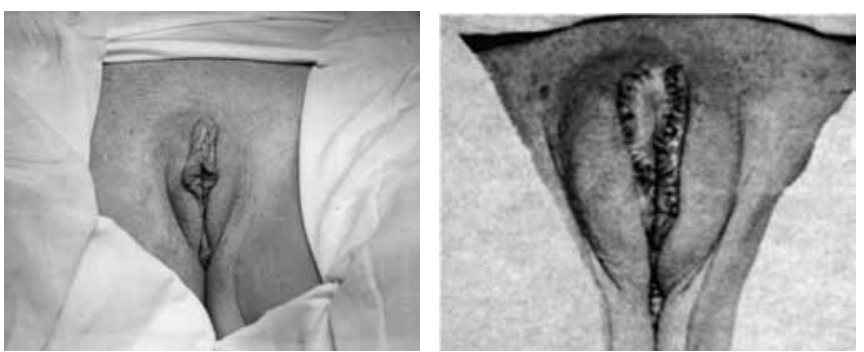

Figura 7 - Paciente de 45 anos de idade, apresentando hipertrofia tipo I dos pequenos lábios e o clitóris enclausurado por excesso de pele.. Pós-operatório imediato pós-ressecção em " $S$ " dos pequenos lábios e dos excessos cutâneos sobre o clitóris.
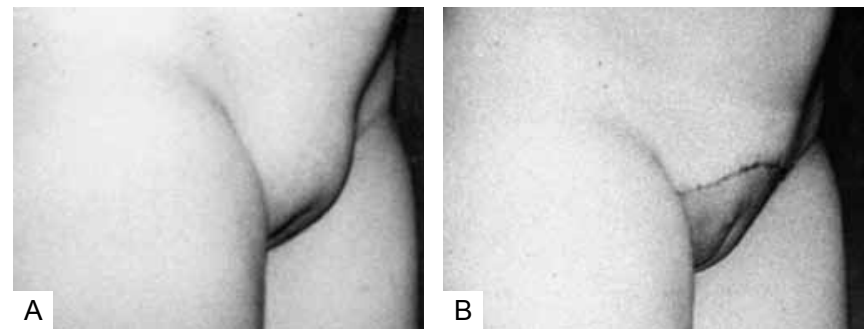

Figura 8 - Paciente de 23 anos de idade, vista lateral do aspecto volumoso do púbis e dos grandes lábios. B: Duas semanas de pós-operatório de lipoescultura com seringa dos grandes lábios e púbis associada ao "lifting" concomitante do púbis mediante ressecção arciforme no limite superior da região.
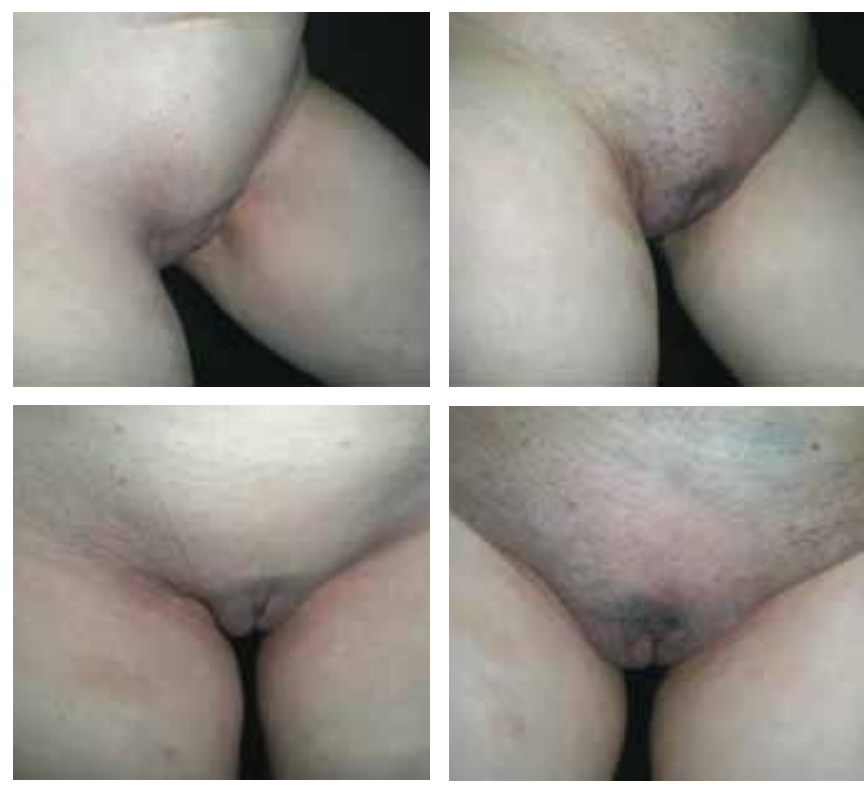

Figura 9 - Vista anterior lateral e frontal de paciente com 49 anos de idade e com hipotrofia do púbis e dos grandes lábios.

Pós-operatório de uma semana, autoimplante de $120 \mathrm{cc}$ de gordura no púbis e 30 cc em cada grande lábio.
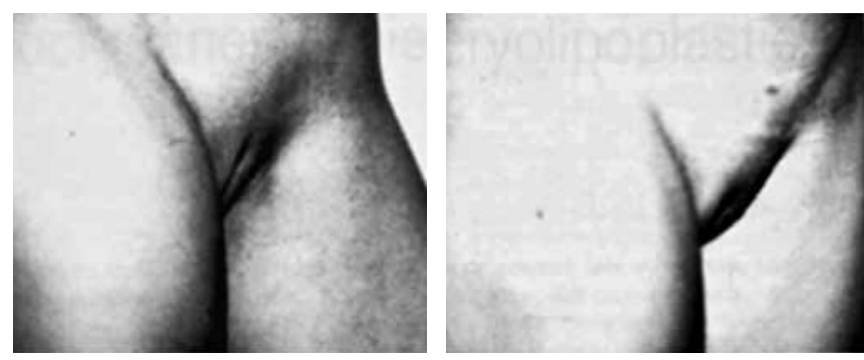

Figura 10 - Vista lateral de hipotrofia do púbis e dos grandes lábios em paciente em que foram injetados $100 \mathrm{ml}$ de gordura no púbis e $20 \mathrm{ml}$ em cada lábio maior num único ato cirúrgico. Paciente de 29 anos de idade e PO de um ano. 


\section{Pubisplastia e plástica da genitália externa masculina}

Nos volumes adiposos do púbis, a lipoescultura com seringa tem sido utilizada após a demarcação e anestesia local, seguindo a mesma rotina de aplicação já registrada (Figuras 11A e 11B). Curativo semicompressivo é mantido nas primeiras 24 horas, combinado a bolsas geladas logo após a cirurgia durante 15 minutos, cinco vezes ao dia, nos primeiros sete dias. Drenagem linfática é indicada nos primeiros 15 dias de pós-operatório.

Nas hipotrofias do pênis, o tratamento compreende lipoenxertia após tratamento prévio da gordura com a eliminação do sangue residual da gordura retirada da área doadora. A lipoenxertia é realizada em um único tempo operatório, sob o delgado tecido celular subcutâneo, 50 a $100 \mathrm{ml}$ de gordura são implantados através de uma agulha de intracat $\mathrm{N}: 12$, não ultrapassando $100 \mathrm{ml}$ por sessão. Em uma única aplicação, a gordura é injetada no sentido circular até atingir o volume desejado, seguida de manipulação digital para a distribuição uniforme ao longo do corpo peniano. Apenas se utiliza micropore no local da infiltração, não há necessidade de curativos, pois estes dificultam o asseio, que deve ser rigoroso. Bolsa de água fria dentro da rotina já descrita (Figuras 12A a 12D, 13). Importante informar os pacientes que não haverá aumento mais de $5 \mathrm{~cm}$ de circunferência do pênis após o tratamento e estabilização da gordura injetada.

Sinéquias no sulco peno-escrotal são operadas mediante zetaplastia e sutura com pontos isolados de Vycril 4.0, seguida de curativo e compressas geladas seguindo a rotina descrita (Figuras 14A a 14C).

Lesões cutâneas tipo hemangioma, após biopsia previa, são tratadas com Erbium Yag Laser, mediante três passadas (Figuras 15A e 15B). Não são usados curativos de qualquer natureza, porém prescreve-se aplicação de pomada tipo colagenase, três vezes ao dia, além de assepsia local.

Nos casos de agenesia e hipogenesia testicular uni ou bilateral, a via de acesso é uma incisão em "S" na rafe da bolsa escrotal, seguida de dissecção na área receptora maior do que o volume da prótese de silicone e sutura em dois planos: pontos isolados Vycril 4-0 com fio absorvível, que elimina o espaço morto ao redor da prótese, e pontos isolados na pele com Nylon 5-0 (Figuras 16A e 16B). Inclusão de uma ou duas próteses testiculares de silicone no mesmo tempo operatório varia com a patologia.

Todos os casos receberam antibioticoterapia a base de $1 \mathrm{~g}$ de cefalotina, duas horas antes da cirurgia, via intramuscular ou endovenosa, e $4 \mathrm{~g}$ diários, por sete dias, via oral. Antiinflamatório (diclofenato de sódio) $70 \mathrm{mg}$, a cada 8 horas, durante uma semana, foi prescrito. Crioterapia com bolsa térmica gelada, 6 vezes ao dia, durante 10 minutos, também está indicada. Atividades esportivas, piscina, mar e sexuais foram liberadas somente 40 dias após a cirurgia.
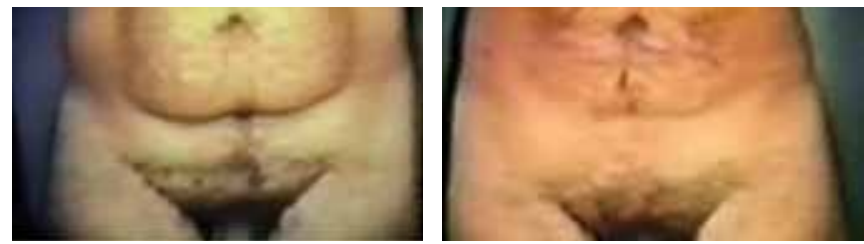

Figura 11 - Aspecto pré-operatório e de um mês de pósoperatório de paciente do sexo masculino, de 33 anos de idade, com lipodistrofia pubiana e da região periumbilical, submetido a lipoaspiração num único tempo operatório, com nítida redução do volume.
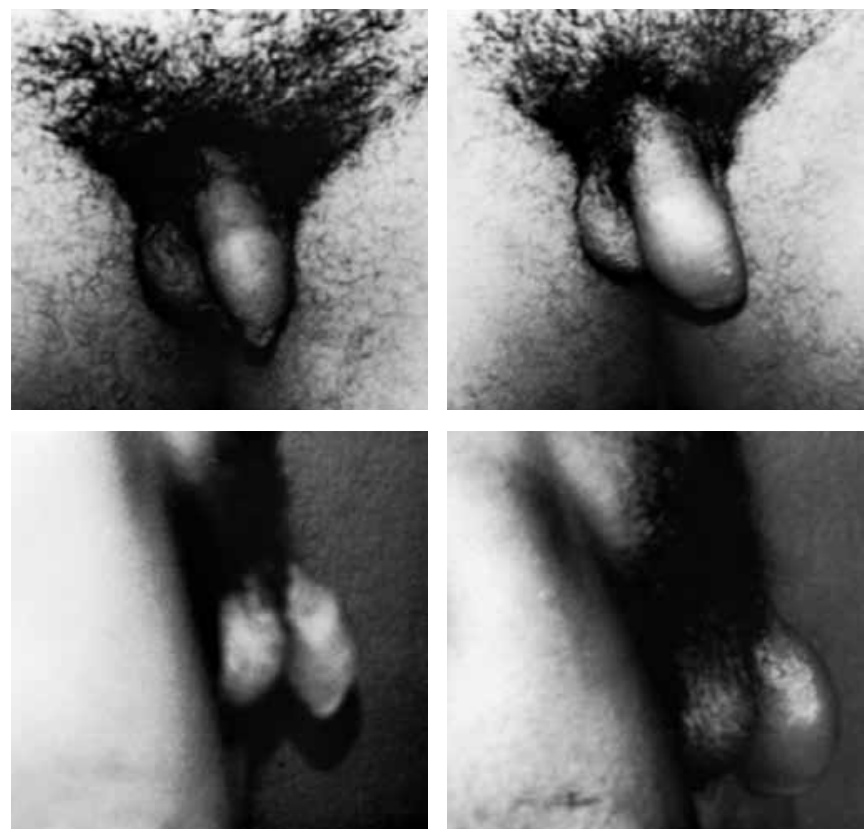

Figura 12 - Aspecto pré-operatório e de um ano de pósoperatório, vista anterior e lateral de paciente com 30 anos de idade submetido a injeção $80 \mathrm{cc}$ de gordura no pênis numa única sessão, com nítido aumento de volume circunferencial e baixo indice de reabsorção.
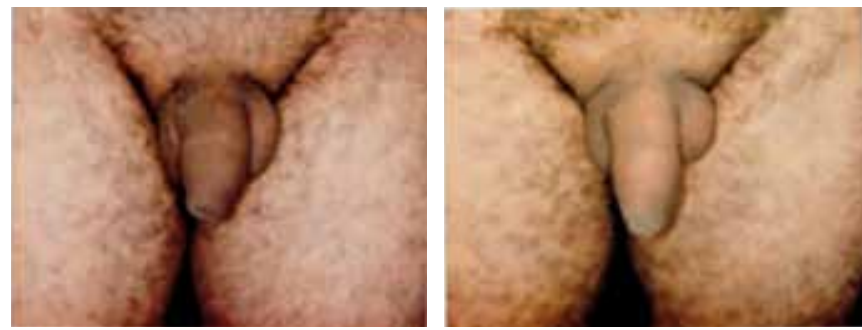

Figura 13 - Pós-operatório de três meses e de dois anos no mesmo paciente de 39 anos de idade, que recebeu $100 \mathrm{ml}$ de gordura autóloga, comprovando reduzido índice de absorção. 


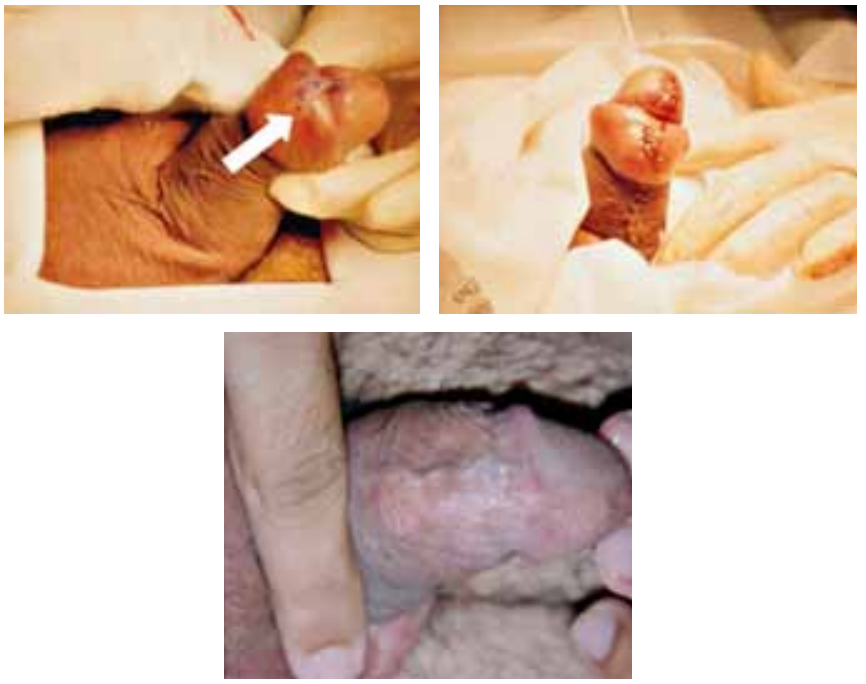

Figura 14 - Sinéquia no freio bálano prepucial: Zetaplastia após uma semana, ainda com edema e pós-operatório após um ano, paciente com 33 anos de idade. Não teve cirurgia prévia de fimose.
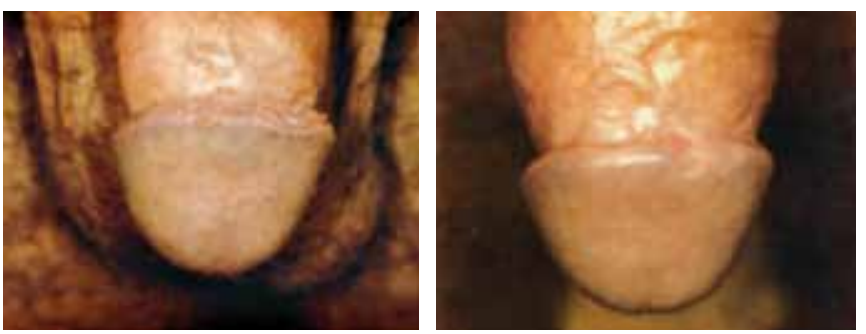

Figura 15 - Pré-operatório num paciente de 28 anos de idade e dois anos de pós tratamento de hemangioma no limite do sulco balânico, mediante uma aplicação e três passadas de Erbium Yag Laser.
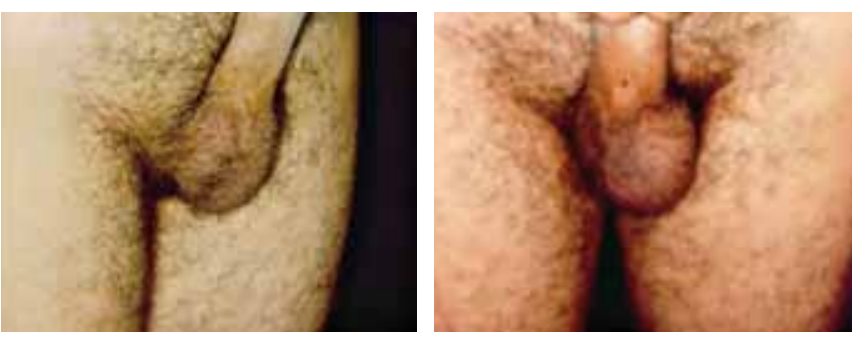

Figura 16 - Pré e pós-operatório de um mês de implante unilateral de silicone com via de acesso na linha mediana da bolsa escrotal. Fibrose residual ainda presente.

\section{DISCUSSÃO}

A nossa casuística de vinte anos registra $56,3 \%$ das pacientes submetidas à redução dos excessos cutâneos dos pequenos lábios, demonstrando a importância dessas dismorfias nas mulheres. Aparentemente, é uma cirurgia de simples resolução, entretanto os limites de ressecção são estreitos. Em outras palavras, ressecar em excesso pode trazer consequências locais, como vaginites crônicas, além dos efeitos psicológicos negativos nestas mulheres. As Figuras 17 a 18 ilustram as consequências das ressecções em excessos. Pequenos lábios com menos de $1,5 \mathrm{~cm}$ não determinam um "tamponamento" eficaz no intróito vaginal, que fica mais vulnerável as infecções. A classificação em quatro tipos de pequenos lábios pelas dimensões é didaticamente útil. Dada as características teciduais dos grandes e pequenos lábios, as ressecções em "S suave" têm oferecido melhor mimetismo com o aspecto natural da vulva.

Os fios de sutura têm sido sempre com fios absorvíveis, para evitar o desconforto durante a remoção. Finalmente, na cirurgia de correção de hipertrofia dos pequenos lábios, deixar um lado maior do que o outro de 1 a $1,5 \mathrm{~cm}$ imita ainda mais a anatomia natural.

As outras alterações morfológicas, como a distrofia do púbis e dos grandes lábios da vulva, quer por aumento de volume, quer o inverso combinados ou não com a flacidez local, fazem parte das queixas de suas portadoras, que buscam na cirurgia a solução estética e a autoconfiança para se exporem nas atitudes normais de suas vidas.

Alipoaspiração, a lipoenxertia, as ressecções dos excessos e o retorno do turgor da pele compõem os procedimentos descritos neste artigo.

Nossa experiência com enxertos de gordura aspirada e injetada com seringa tem sido mais gratificante e eficaz, pois, apesar de haver absorção, tem sido menor, quando comparada ao sistema convencional com o uso de aparelho. Temos observado integração de aproximadamente $50 \%$ da gordura injetada com seguimento de dois anos. A ressecção dos excessos cutâneos que envolvem o clitóris não deve atingi-lo, dada a grande inervação existente, evitando-se o comportamento da sensibilidade. O objetivo é obter a semelhança com o aspecto da vulva no nível dos grandes lábios e centralmente posicionado.

Nas hipotrofias de pênis, os enxertos de gordura têm sido a forma de tratamento menos agressiva cirurgicamente (Figura 19).

A literatura registra caso de necrose peniana com volume injetado num único tempo superior a $100 \mathrm{ml}^{13}$.

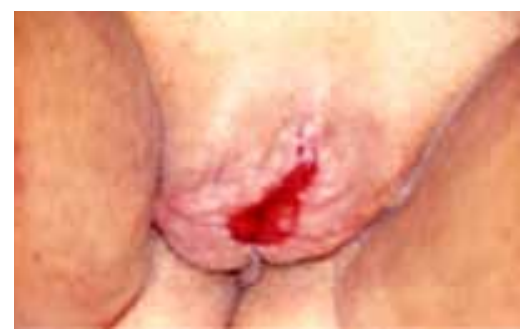

Figura 17 - Área cruenta nos grandes lábios numa paciente de 68 anos de idade com um ano de evolução, pós-ressecção em excesso e deiscência de sutura (perda total dos pequenos lábios) para correção de hipertrofia de pequenos lábios, em serviço de ginecologia e obstetrícia. 

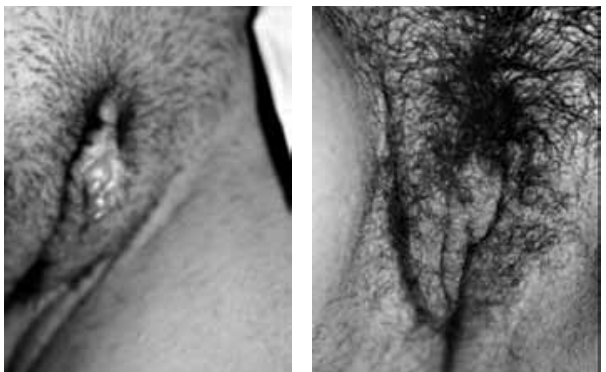

Figura 18 - Sequela de correção de hipertrofia dos pequenos lábios realizada em outro serviço de cirurgia plástica, retirada em excesso do pequeno lábio esquerdo e ressecção insuficiente, deixando excessos no pequeno lábio direito, com um aspecto de "micropênis". Pós-operatório após um ano, paciente ficou satisfeita com o resultado e não desejava submeter-se a um enxerto de pele na tentativa de recompor o pequeno lábio esquerdo.

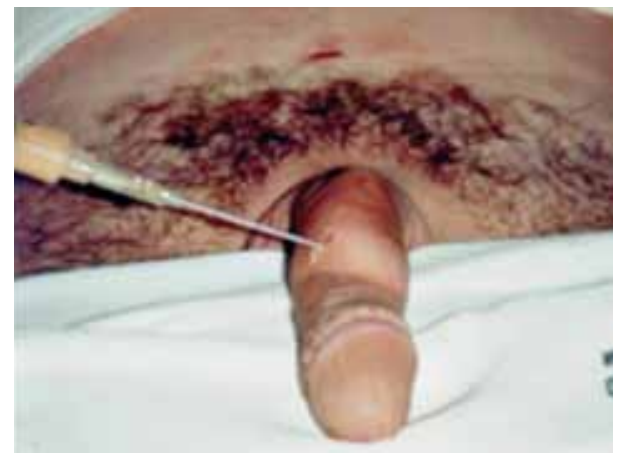

Figura 19 - Autoimplante de gordura no subcutâneo em pênis, após rigorosa limpeza com soro fisiológico da gordura aspirada com seringa de 60cc.

\section{CONCLUSÕES}

Os diversos tipos de cirurgias no púbis e nos genitais externos, de ambos sexos, descritos e ilustrados neste artigo, expressam duas décadas de experiência.
Os procedimentos reportados tiveram por finalidade reduzir e mesmo eliminar as distorções morfológicas congênitas e adquiridas. Apesar de aparente facilidade técnica, a quantidade de tecido a ser ressecada ou mantida, bem como o volume de tecido adiposo a ser aspirado ou injetado faz com que estes procedimentos estejam situados entre limites estreitos de segurança. Quando estes limites são ultrapassados, podem deixar problemas de difícil solução anatômica e consequências psicológicas pouco previsíveis.

\section{REFERÊNCIAS}

1. Menezes W. A sexualidade no terceiro milênio. Aracaju: J Andrade Ltda;2000.

2. FournierFP.Liposculpture the syringe technique. 1sted.Paris:Arnette Blackwell;1991.

3. Felicio Y. Labial surgery. Aesthetic Surg J. 2007;27(3):322-8.

4. Franco T, Franco D. Hipertrofia de ninfas. J Bras Ginecol. 1993;103(5):163-5.

5. Kaluf R, Araújo GAZ, Martins DL, Campos LCB, Magalhães RC, Santos Jr AJ. Tratamento da região pubiana na abdominoplastia de pacientes após grande perda ponderal. Rev Bras Cir Plást. 2008;23(4):302-4.

6. Nóbrega ESS, Silva HLA. Rejuvenescimento da região pudenda, associado ou não a dermolipectomia abdominal. Rev Bras Cir Plást. 2009;24(3):351-6.

7. Martuscelli OJD, Gomes CHR. Vulvectomia radical: abordagem e complicações. Rev Bras Cir Plást. 2009;24(sup1):51.

8. Pinho PR, Araújo ESF. Criptococoma: relato de caso e revisão de literatura. Rev Bras Cir Plást. 2009;24(supl):52.

9. Nassif T Amarante L, Chang YC, Aniceto M, Cintra H. Faloplastia total microcirúrgica com retalho antebraquial e implante peniano em um único tempo cirúrgico: relato de caso. Rev Bras Cir Plast. 2009;24(3):385-8.

10. Mottura A. Labia majora hypertrophy. Aesthetic Plast Surg. 2009;33(6):859-63.

11. Blank J. Femalia. San Francisco:Down There Press;1993.

12. Felicio Y.Chirurgie intime. Rev Chir EsthLang Franc. 1992; XVII(67): 37-43.

13. Abecassis M, Perez EH. La lipopenosculpture augmantation de la talle du pénis. Annales de Lipoplastie. 1er ed. Marseille:Solal;1996.

Correspondência para:

Yhelda de Alencar Felicio

Rua Professor Dias da Rocha, 1200 - Aldeota -Fortaleza, CE, Brasil - CEP60170-310

E-mail: yheldafelicio@secrel.com.br 